ARTICLE

\title{
Ternary nickel-tungsten-copper alloy rivals platinum for catalyzing alkaline hydrogen oxidation
}

\author{
Shuai Qin ${ }^{1,5}$, Yu Duan ${ }^{1,5}$, Xiao-Long Zhang (10 1,5, Li-Rong Zheng ${ }^{2}$, Fei-Yue Gao ${ }^{1}$, Peng-Peng Yang ${ }^{1}$, \\ Zhuang-Zhuang Niu', Ren Liu ${ }^{3}$, Yu Yang${ }^{1}$, Xu-Sheng Zheng ${ }^{4}$, Jun-Fa Zhu (i) ${ }^{4}$ \& Min-Rui Gao (i) ${ }^{1 凶}$
}

Operating fuel cells in alkaline environments permits the use of platinum-group-metal-free (PGM-free) catalysts and inexpensive bipolar plates, leading to significant cost reduction. Of the PGM-free catalysts explored, however, only a few nickel-based materials are active for catalyzing the hydrogen oxidation reaction (HOR) in alkali; moreover, these catalysts deactivate rapidly at high anode potentials owing to nickel hydroxide formation. Here we describe that a nickel-tungsten-copper $\left(\mathrm{Ni}_{5.2} \mathrm{WCu}_{2.2}\right)$ ternary alloy showing $\mathrm{HOR}$ activity rivals $\mathrm{Pt} / \mathrm{C}$ benchmark in alkaline electrolyte. Importantly, we achieved a high anode potential up to $0.3 \mathrm{~V}$ versus reversible hydrogen electrode on this catalyst with good operational stability over 20 h. The catalyst also displays excellent CO-tolerant ability that Pt/C catalyst lacks. Experimental and theoretical studies uncover that nickel, tungsten, and copper play in synergy to create a favorable alloying surface for optimized hydrogen and hydroxyl bindings, as well as for the improved oxidation resistance, which result in the HOR enhancement.

\footnotetext{
${ }^{1}$ Division of Nanomaterials \& Chemistry, Hefei National Laboratory for Physical Sciences at the Microscale, University of Science and Technology of China, Hefei, China. ${ }^{2}$ Beijing Synchrotron Radiation Facility, Institute of High Energy Physics, Chinese Academy of Sciences, Beijing, China. ${ }^{3}$ Department of Materials Science and Engineering, University of Science and Technology of China, Hefei, China. ${ }^{4}$ National Synchrotron Radiation Laboratory, University of Science and Technology of China, Hefei, China. ${ }^{5}$ These authors contributed equally: Shuai Qin, Yu Duan, Xiao-Long Zhang. ${ }^{凶}$ email: mgao@ustc.edu.cn
} 
O ver the past 30 years, the proton exchange membrane fuel cell (PEMFC) technology has developed rapidly, resulting in the first commercial sales of fuel-cell powered cars in 2015 (ref. ${ }^{1}$ ). Although great success, the mass market penetration by such zero-emission vehicles is currently hindered by the absence of inexpensive materials to replace costly platinum (Pt)based catalysts, which are responsible for $\sim 46 \%$ of the stack $\operatorname{cost}^{2}$. Extensive research has been conducted using various strategies to reduce the $\mathrm{Pt}$ loading ${ }^{3-5}$, but the acidic environment largely constrains the choice of catalytic materials that perform stably in PEMFCs. This shortcoming can be overcome by switching the operating environment from an acid to alkaline one-the resultant anion exchange membrane fuel cells (AEMFCs) allow for the use of platinum group metal-free (PGM-free) catalysts, thus enabling significant cost reduction ${ }^{6}$. Indeed, some PGM-free materials have been observed to catalyze the oxygen reduction reaction (ORR) comparable to Pt for the AEMFC cathode ${ }^{7-10}$. However, at the AEMFC anode, the activity of the hydrogen oxidation reaction (HOR) on $\mathrm{Pt}$ is inherently slower by $\sim 100$ times than that in acidic environment ${ }^{11,12}$, which demands much higher Pt loadings $\left(0.4 \mathrm{mg}_{\mathrm{Pt}} \mathrm{cm}^{-2}\right.$ at AEMFC anode versus $0.03 \mathrm{mg}_{\mathrm{Pt}} \mathrm{cm}^{-2}$ at PEMFC anode) to reach similar fuel cell performance ${ }^{13}$. At present, the lack of highly active and stable PGM-free HOR catalysts in alkaline environments hampers the progress towards the AEMFC implementation ${ }^{14}$.

Substantial effort has been devoted to searching HOR catalysts composed solely of earth-abundant elements, whereas PGM-free catalysts that show HOR activity in alkali are rather rare ${ }^{15}$. Nickel (Ni)-based compounds are currently the materials with the most promise as catalysts that drive the HOR in alkaline environments ${ }^{16}$. In 1960s, Raney Ni was first explored as HOR catalyst in liquid alkaline fuel cells under extreme alkalinity $(6 \mathrm{M}$ $\mathrm{KOH})$, but its activity was very low ${ }^{17-19}$. Since then, the HOR performance of Ni-based catalysts has been gradually improved via diverse methods, yielding catalysts such as $\mathrm{CoNiMo}{ }^{20}, \mathrm{MoNi}_{4}$ and $\mathrm{WNi}_{4}{ }^{21}, \mathrm{NiMo} / \mathrm{C}^{22}, \mathrm{Ni} / \mathrm{NiO} / \mathrm{C}^{23}, \mathrm{Ni} / \mathrm{N}$-doped carbon nanotubes ${ }^{13}, \mathrm{CeO}_{2} / \mathrm{Ni}$ heterostructures ${ }^{24}, \mathrm{Cr}$-modified $\mathrm{Ni}^{25}$, and $\mathrm{Ni}_{3} \mathrm{~N}$ nanoparticles ${ }^{26,27}$. Despite marked progress, many of these Ni-based HOR catalysts deactivate quickly above $0.1 \mathrm{~V}$ versus reversible hydrogen electrode (RHE) owing to the formation of surface hydroxides ${ }^{28}$. To generate adequate power density, however, HOR catalysts should remain stable to at least $0.3 \mathrm{~V}$ versus $\mathrm{RHE}^{2}$, which could also largely mitigate the risk of passivation of the stack under transient conditions. Unfortunately, there is no PGM-free HOR catalyst with operating stability up to $0.3 \mathrm{~V}$ versus RHE has been reported thus far.

Here we report that $\mathrm{Ni}_{5.2} \mathrm{WCu}_{2.2}$ nanotubes (NTs) - a ternary nickel-tungsten-copper alloy-can catalyze the HOR in alkaline electrolyte highly efficient and stable. We find that the $\mathrm{Ni}_{5.2} \mathrm{WCu}_{2.2}$ catalyst achieves higher HOR activity than a commercial $\mathrm{Pt} / \mathrm{C}$ counterpart. Importantly, stability window up to 0.3 $\mathrm{V}$ versus RHE was realized on this catalyst. At this potential, a considerable current density of $16.5 \mathrm{~mA} \mathrm{~cm}^{-2}$ could be held over 20 hours without notable decay. Moreover, this alloyed catalyst also exhibits high tolerance to $20,000 \mathrm{ppm}$ CO impurity. The extraordinary efficiency of $\mathrm{Ni}_{5.2} \mathrm{WCu}_{2.2}$ exceeds that of previously reported PGM-free HOR catalysts.

\section{Results}

Synthesis and characterization of catalyst. Very recently, our group has reported bimetallic $\mathrm{MoNi}_{4}$ and $\mathrm{WNi}_{4}$ nanoalloys with notable activity toward the alkaline HOR, but such binary alloys lose activity above $0.2 \mathrm{~V}$ versus RHE owing to the surface oxidation $^{21}$. Previous studies suggested an alloying-based approach for improved stability of catalysts by tuning the microstructures of the host metals ${ }^{29-32}$. For examples, alloying Mo with $\mathrm{Pt}_{3} \mathrm{Ni}$ (111) can mitigate the Ni leaching during electrochemical process, enabling greatly enhanced ORR stability ${ }^{31}$. Chorkendorff et al. identified that alloys of Pt and rare earths are stable ORR catalysts because of their very negative alloying energy $E_{\mathrm{a}}$ that limits dissolution ${ }^{32}$. We thus seek to widen the stability window of binary $\mathrm{Ni}-\mathrm{W}$ catalyst through alloying with additional element to form new structure that resists surface oxidation during HOR operation. Prior studies have shown that HOR activity and stability can be improved largely in alkaline electrolytes when using $\mathrm{Cu}$ to partially replace noble metals (e.g., $\mathrm{PdCu}$ nanoparticles ${ }^{33}$ and $\mathrm{Pt} / \mathrm{Cu}$ nanowires ${ }^{34}$ ). Moreover, Dekel et al. reported that $\mathrm{Cu}$ in alloys often dissolves at higher anode potentials as compared to other metals such as $\mathrm{Mo}^{28}$. We thus speculate that $\mathrm{Cu}$ may play an important role in enhancing the HOR activity and stability. Hence, we decide to introduce $\mathrm{Cu}$ to form ternary $\mathrm{Ni}-\mathrm{W}-\mathrm{Cu}$ alloy and explore its alkaline $\mathrm{HOR}$ property.

To synthesize the catalyst, $\mathrm{Cu}$ foam was immersed in $1 \mathrm{M} \mathrm{KOH}$ for an anodization process to grow $\mathrm{Cu}(\mathrm{OH})_{2}$ nanowires throughout the substrate (Supplementary Figs. 1 and 2). The resulting indigo foam was consequently treated hydrothermally with $\mathrm{Ni}\left(\mathrm{NO}_{3}\right)_{2} \cdot 6 \mathrm{H}_{2} \mathrm{O},\left(\mathrm{NH}_{4}\right)_{6} \mathrm{H}_{2} \mathrm{~W}_{12} \mathrm{O}_{40} \cdot \mathrm{xH}_{2} \mathrm{O}$, and $\mathrm{CO}\left(\mathrm{NH}_{2}\right)_{2}$ in deionized water at $130^{\circ} \mathrm{C}$ for $8 \mathrm{~h}$. Then, the obtained green $\mathrm{NiW}-\mathrm{Cu}(\mathrm{OH})_{2}$ precursor (Supplementary Figs. 3 and 4 ) was annealed in hydrogen/argon $\left(\mathrm{H}_{2} / \mathrm{Ar}: 5 / 95\right)$ atmosphere at $500^{\circ} \mathrm{C}$ for $1 \mathrm{~h}$ to yield ternary Ni-W-Cu alloy (Fig. 1a). This simple synthetic approach provides good scalability. We synthesized a 3 $\mathrm{cm} \times 10 \mathrm{~cm} \mathrm{Ni}-\mathrm{W}-\mathrm{Cu}$ alloy foam by using scaled-up reactors, which shows good fidelity of the product, implying a potential industry-level use (Fig. 1b and Supplementary Fig. 5).

The achieved electrode consists of numerous uniform Ni-W$\mathrm{Cu}$ alloy nanofibers with length up to $10 \mu \mathrm{m}$ when imaged by scanning electron microscopy (SEM) (Fig. 2a and Supplementary Fig. 6). Each fiber possesses a very rough surface that is made up of whiskerette particles. Low-resolution transmission electron microscopy (TEM) unveils that the center of a representative fiber appears brighter, demonstrating that it is hollow (Fig. 2b). The formation of hollow-fibers was caused by the outward diffusion of $\mathrm{Cu}$ in the NiW-Cu$(\mathrm{OH})_{2}$ precursor to produce $\mathrm{Ni}-\mathrm{W}-\mathrm{Cu}$ alloy during annealing process. Selected-area electron diffraction (SAED) analysis of a whisker reveals its high-crystalline structure (Up inset in Fig. 2b), which agrees with our atomic-resolution high-angle annular dark-field scanning transmission electron microscopy (HAADF-STEM) result that shows continuous lattice fringes without surface defects (Down inset in Fig. 2b). In Fig. 2c, the STEM measurements reveal that alloyed whiskerette particles bounded closely to form distinct grain boundaries. Energydispersive X-ray (EDX) spectrum elemental mapping displays a uniform, uncorrelated spatial distribution of $\mathrm{Ni}, \mathrm{W}$, and $\mathrm{Cu}$ (Fig. 2c and Supplementary Fig. 7). The weak O signal could originate from the adsorbed $\mathrm{O}$ and slight surface oxidation when exposing the sample in the air (Supplementary Fig. 8).

We performed X-ray diffraction (XRD) measurements of the collected $\mathrm{Ni}-\mathrm{W}-\mathrm{Cu}$ alloy powder and observed a high-crystallinity face-centred cubic structure (Fig. 2d). Compared to (111), (200), and (220) reflections of Ni nanoparticles, the diffraction peaks are shifted to lower angles in $\mathrm{Ni}-\mathrm{W}-\mathrm{Cu}$ alloy, indicating a higher lattice parameter caused by the addition of atoms with larger radius. Using similar synthetic method, we also prepared Ni-W alloy with cubic $\mathrm{Ni}_{17} \mathrm{~W}_{3}$ phase (Fig. $2 \mathrm{~d}$ and Supplementary Fig. 9), whose diffraction peaks sit between those of $\mathrm{Ni}$ nanoparticles (Fig. 2d and Supplementary Fig. 10) and Ni-W$\mathrm{Cu}$ alloy. Given that the atomic radius follows the sequence of $\mathrm{Ni}$ $<\mathrm{Cu}<\mathrm{W}$, we predict more $\mathrm{W}$ atoms in $\mathrm{Ni}-\mathrm{W}-\mathrm{Cu}$ than in $\mathrm{Ni}_{17} \mathrm{~W}_{3}$. Our inductively coupled plasma atomic emission 

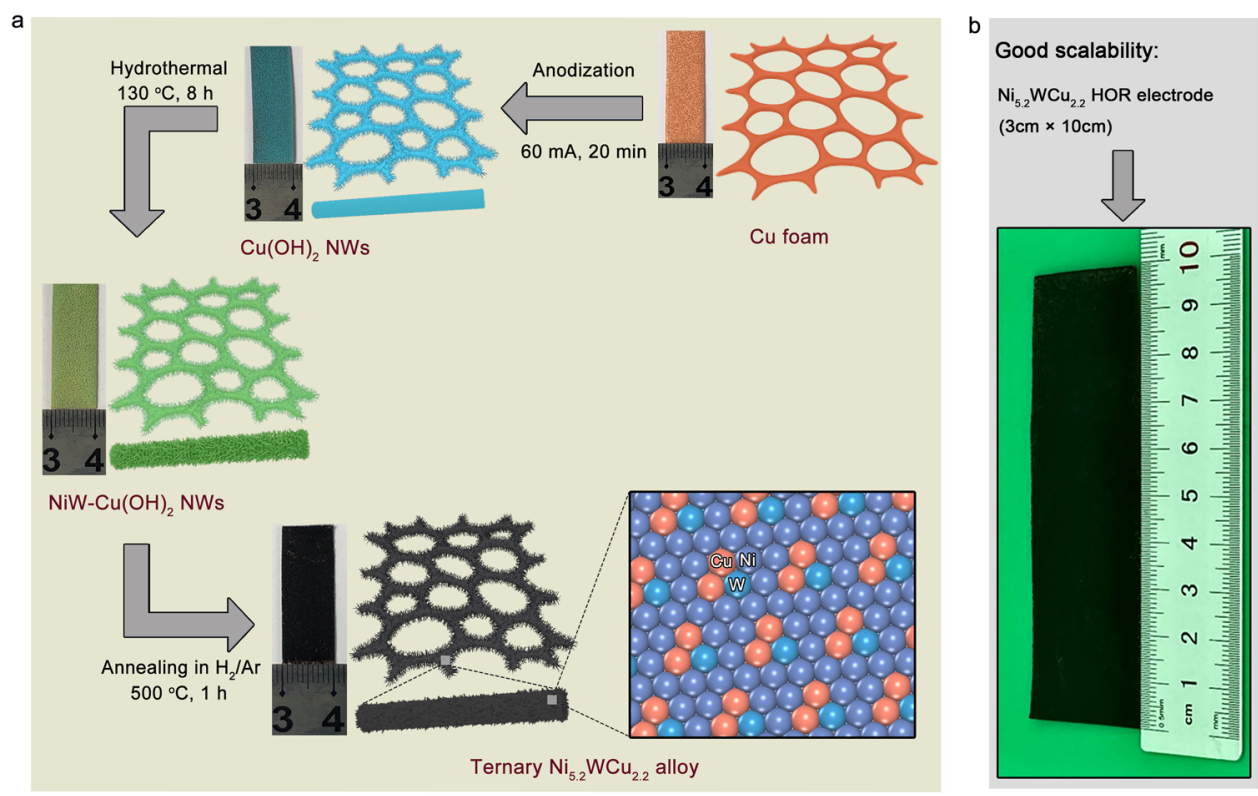

Fig. 1 Synthesis of ternary $\mathbf{N i}_{\mathbf{5 . 2}} \mathbf{W C u}_{\mathbf{2 . 2}}$ alloy. a Schematic illustration of the synthesis of $\mathrm{Ni}_{5.2} \mathrm{WCu}_{2.2}$ alloy monolith. b Scaled-up synthesis of $\mathrm{Ni}_{5.2} \mathrm{WCu}_{2.2}$ alloy monolith with a size of $3 \mathrm{~cm} \times 10 \mathrm{~cm}$ using the identical protocol.

spectroscopy (ICP-AES) analysis gives a $\mathrm{Ni}: \mathrm{W}: \mathrm{Cu}$ ratio of 5.2:1:2.2 for $\mathrm{Ni}-\mathrm{W}-\mathrm{Cu}$ alloy, which agrees well with EDX measurements and confirms our speculation. Thereafter, we assign the obtained ternary alloy as $\mathrm{Ni}_{5.2} \mathrm{WCu}_{2.2}$.

Alloying-based design has been demonstrated to alter catalytic properties by modulating the electronic structures of host and alloyed metals, leading to a cooperative interplay that tunes the adsorption energies of critical intermediates for enhanced catalytic reactivity ${ }^{35-37}$. We probed the work function of $\mathrm{Ni}_{5.2} \mathrm{WCu}_{2.2}, \mathrm{Ni}_{17} \mathrm{~W}_{3}$ and $\mathrm{Ni}$ catalysts by Kelvin probe force microscopy ${ }^{88,39}$ (KPFM; Supplementary Fig. 11). A clean highly oriented pyrolytic graphite (HOPG) with work function value of $4.6 \mathrm{eV}$ was used as a reference ${ }^{39}$. Figure $2 \mathrm{e}$ presents the measured surface potentials for the studied samples, which correspond to a work function value of 4.54 for $\mathrm{Ni}_{5.2} \mathrm{WCu}_{2.2}$, versus $4.71 \mathrm{eV}$ for $\mathrm{Ni}_{17} \mathrm{~W}_{3}$ and $4.80 \mathrm{eV}$ for $\mathrm{Ni}$ (Inset in Fig. 2e), consistent with our calculated results (Supplementary Fig. 12). The lower work function of $\mathrm{Ni}_{5.2} \mathrm{WCu}_{2.2}$ suggests its modified electronic structure that allows for a faster electron transfer and thus enhanced catalytic ability ${ }^{40}$. To reveal the impact of ternary alloy effect on the chemical and structural environments of $\mathrm{Ni}$, we performed the X-ray absorption spectroscopy. Figure $2 \mathrm{f}$ shows the X-ray absorption near-edge spectroscopy measurements of the $\mathrm{Ni}$ Kedge from $\mathrm{Ni}_{5.2} \mathrm{WCu}_{2.2}, \mathrm{Ni}_{17} \mathrm{~W}_{3}$, and freshly-prepared $\mathrm{Ni}$ samples, as well as that from a $\mathrm{Ni}$ foil used for comparison. Adsorption features that are present in the spectra of our freshlyprepared $\mathrm{Ni}$ and $\mathrm{Ni}$ foil reference are similar. By contrast, a substantial increase in the white lines was observed for $\mathrm{Ni}_{5.2} \mathrm{WCu}_{2.2}$ and $\mathrm{Ni}_{17} \mathrm{~W}_{3}$, indicating electron donation from $\mathrm{Ni}$ to $\mathrm{W}$ and $\mathrm{Cu}$ upon alloying ${ }^{41}$. We probed the radial structure function around Ni by Fourier transform (FT) of extended X-ray absorption fine-structure (EXAFS) spectra (Fig. 2g, Supplementary Fig. 13). A profound peak at $\sim 2.1 \AA$ can be attributable to the $\mathrm{Ni}-\mathrm{Ni}$ and $\mathrm{Ni}-\mathrm{W} / \mathrm{Cu}$ bonds in $\mathrm{Ni}_{5.2} \mathrm{WCu}_{2.2}$ and $\mathrm{Ni}_{17} \mathrm{~W}_{3}$ alloys $^{21,42}$. The intensity of this peak decreases upon alloying $\mathrm{Ni}$ with $\mathrm{W}$ and $\mathrm{Cu}$ to form $\mathrm{Ni}_{5.2} \mathrm{WCu}_{2.2}$, which represents damped coordination structure of Ni. Furthermore, our Ni Kedge EXAFS fittings reveal that the first-shell $\mathrm{Ni}-\mathrm{W} / \mathrm{Cu}$ coordination number decreases from freshly-prepared $\mathrm{Ni}$ ( 10.8) to $\mathrm{Ni}_{17} \mathrm{~W}_{3}(\sim 9.0)$ and then to $\mathrm{Ni}_{5,2} \mathrm{WCu}_{2.2}(\sim 8.7)$ (Fig. 2h,
Supplementary Fig. 14, Supplementary Table 1). We surmise the lower coordination number attributable to the highly nanostructured hollow structure of $\mathrm{Ni}_{5.2} \mathrm{WCu}_{2.2}$, and estimate that more active sites exist on the ternary alloy that would modify the adsorption ability of HOR intermediates.

Evaluation of HOR performance. We evaluated HOR activity and stability of the ternary $\mathrm{Ni}_{5.2} \mathrm{WCu}_{2.2}$ alloy in a standard threeelectrode setup (Supplementary Fig. 15), using $\mathrm{H}_{2}$-saturated $0.1 \mathrm{M}$ aqueous $\mathrm{KOH}$ as the electrolyte. The working electrode cuts from large-area $\mathrm{Ni}_{5.2} \mathrm{WCu}_{2.2}$ monolith with a geometric surface area of $\sim 1 \mathrm{~cm}^{2}$ (catalyst loading: $\sim 9.2 \mathrm{mg} \mathrm{cm}^{-2}$ ). Reference measurements of $\mathrm{Ni}_{17} \mathrm{~W}_{3}, \mathrm{Ni}$, and commercial $\mathrm{Pt} / \mathrm{C}(20 \mathrm{wt} \%)$ catalysts were similarly performed for comparison. We used a slow sweep rate of $1 \mathrm{mV} \mathrm{s}^{-1}$ to minimize the capacitive contribution and to guarantee a steady-state measurement. Unless otherwise stated, all electrochemical data were measured without electrode rotation and were $i R$-corrected ( $i$, current; $R$, resistance) for the uncompensated Ohmic drop.

As shown by the linear sweep voltammetry (LSV) curve of $\mathrm{Ni}_{5.2} \mathrm{WCu}_{2.2}$ in $0.1 \mathrm{M} \mathrm{KOH}$, the onset potential for generating HOR current is as low as $0 \mathrm{~V}$ versus RHE, beyond which a sharp increase in anodic current was observed, demonstrating its exceptional energetics for HOR (Fig. 3a). By contrast, $\mathrm{Ni}_{5,2} \mathrm{WCu}_{2,2}$ gives almost no current-voltage feature in $0.1 \mathrm{M}$ KOH saturated by Ar (Supplementary Fig. 16), further confirming that HOR catalysis occurs on this alloy catalyst. Figure $3 \mathrm{a}$ also shows that $\mathrm{Ni}_{5.2} \mathrm{WCu}_{2.2}$ can reach a diffusion-limiting $\mathrm{HOR}$ current density of $\sim 20 \mathrm{~mA} \mathrm{~cm}^{-2}$, whereas $\mathrm{Ni}_{17} \mathrm{~W}_{3}$ exhibits much inferior HOR activity and the single $\mathrm{Ni}$ is almost $\mathrm{HOR}$ inactive. Remarkably, the $\mathrm{Ni}_{5.2} \mathrm{WCu}_{2.2}$ catalyst even surpasses the commercial $\mathrm{Pt} / \mathrm{C}$ catalyst from the kinetic to diffusion-limiting regions. We note that no rotation was applied to our bulky electrodes, suggesting that the Levich equation would not take effect ${ }^{43}$. As a result, the measured diffusion-limiting HOR currents on different catalysts deviate from the theoretical value. We measured a half-wave potential of $39 \mathrm{mV}$ for $\mathrm{Ni}_{5.2} \mathrm{WCu}_{2.2}$, versus $44 \mathrm{mV}$ for $\mathrm{Pt} / \mathrm{C}$ catalyst. The observed striking HOR activity on $\mathrm{Ni}_{5.2} \mathrm{WCu}_{2.2}$ agrees well with the electrochemical 

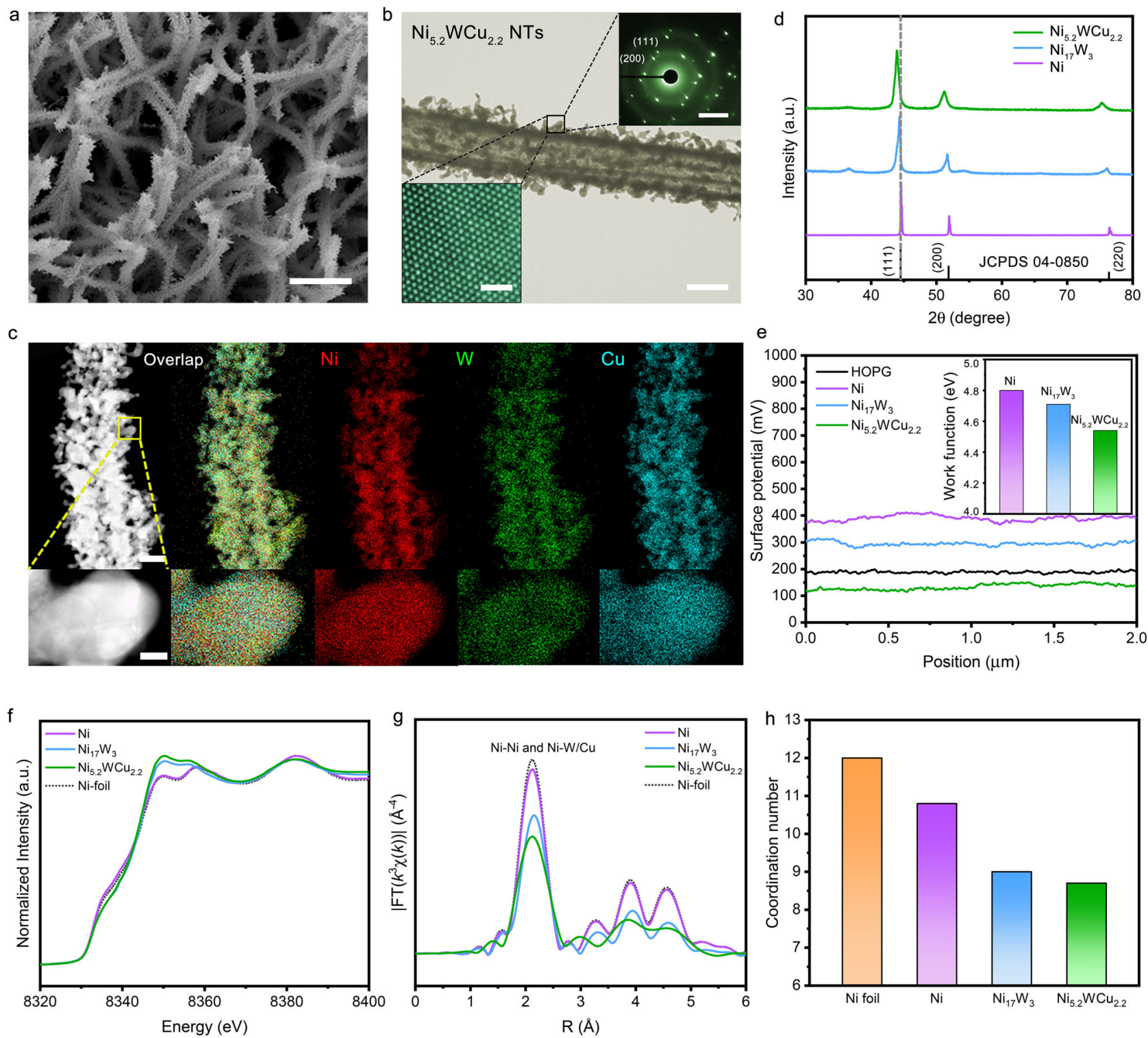

Fig. 2 Characterization and structural analysis. a SEM image of $\mathrm{Ni}_{5.2} \mathrm{WCu}_{2.2}$ alloy. Scale bar, $2 \mu \mathrm{m}$. b TEM image of $\mathrm{Ni}_{5.2} \mathrm{WCu}_{2.2}$ alloy. Scale bar, $250 \mathrm{~nm}$. Insets show SAED pattern (up; scale bar, $51 / \mathrm{nm}$ ) and the atomic-resolution HAADF-STEM image (down; scale bar, $1 \mathrm{~nm}$ ), respectively. c STEM-EDX elemental mappings of $\mathrm{Ni}_{5.2} \mathrm{WCu}_{2.2}$ alloy, showing a uniform spatial distribution of $\mathrm{Ni}, \mathrm{W}$, and $\mathrm{Cu}$. Scale bars, $200 \mathrm{~nm}$ (up) and $20 \mathrm{~nm}$ (down). d XRD patterns of $\mathrm{Ni}_{1} \mathrm{Ni}_{17} \mathrm{~W}_{3}$ and $\mathrm{Ni}_{5.2} \mathrm{WCu}_{2.2}$, respectively. e Surface potential profiles along the white lines in Supplementary Figure 10 for $\mathrm{Ni}_{1}, \mathrm{Ni}_{17} \mathrm{~W}_{3}$,

$\mathrm{Ni}_{5.2} \mathrm{WCu}_{2.2}$ and HOPG reference, respectively. Inset shows the resultant work function values for the studied catalysts. $\mathbf{f}, \mathbf{g}$ Ni K-edge XANES spectra and corresponding Fourier transforms of $k^{3}$-weighted EXAFS spectra for $\mathrm{Ni}_{1} \mathrm{Ni}_{17} \mathrm{~W}_{3}, \mathrm{Ni}_{5.2} \mathrm{WCu}_{2.2}$ and $\mathrm{Ni}$ foil reference. $\boldsymbol{h}$ The average coordination number in the first coordination shell of $\mathrm{Ni}$ atoms for $\mathrm{Ni}, \mathrm{Ni}_{17} \mathrm{~W}_{3}$, and $\mathrm{Ni}_{5.2} \mathrm{WCu}_{2.2}$ by EXAFS spectra curve fitting. The coordination number of $\mathrm{Ni}$ foil reference is 12 .

impedance spectroscopy measurements that yield a small charge transfer resistance of $\sim 3.0 \mathrm{Ohms}$ at $30 \mathrm{mV}$ overpotential (Supplementary Fig. 17).

In Fig. 3a, we show another important observation that we want to highlight in this work: that is, our nanostructured $\mathrm{Ni}_{5.2} \mathrm{WCu}_{2.2}$ catalyst can sustain $\mathrm{HOR}$ reactivity without deactivation up to $0.3 \mathrm{~V}$ versus RHE. Previously, most Ni-based HOR catalysts have been witnessed to lose activity rapidly above $0.1 \mathrm{~V}$ versus RHE owing to hydroxide formation ${ }^{13,28}$. Indeed, scanning LSV positively displays two pronounced peaks starting from $0.2 \mathrm{~V}$ versus RHE for $\mathrm{Ni}_{17} \mathrm{~W}_{3}$ and $0.18 \mathrm{~V}$ versus RHE for $\mathrm{Ni}$ (Inset in Fig. 3a), which correspond to the formation of $\mathrm{Ni}(\mathrm{OH})_{2}$ (ref. ${ }^{44}$ ). The limited tolerance to anode overpotentials poses significant risk of passivation under high current operation, leading to unsatisfied power output ${ }^{2}$. The stability window up to
$0.3 \mathrm{~V}$ versus $\mathrm{RHE}$ for our $\mathrm{Ni}_{5.2} \mathrm{WCu}_{2.2}$ catalyst has not yet been achieved on previous PGM-free HOR catalysts (Fig. 3b), which would largely mitigate the risk of passivation under transient conditions.

We now extract the exchange current density $\left(j_{0}\right)$-the most inherent measure of HOR activity - of various catalysts from linear fitting of micro-polarization regions ( -5 to $5 \mathrm{mV}$; Supplementary Fig. 18). The geometric $j_{0}$ of $11.36 \mathrm{~mA} \mathrm{~cm}^{-2}$ for $\mathrm{Ni}_{5.2} \mathrm{WCu}_{2.2}$ largely surpasses the values of $1.23 \mathrm{~mA} \mathrm{~cm}^{-2}$ for $\mathrm{Ni}_{17} \mathrm{~W}_{3}, 0.14 \mathrm{~mA} \mathrm{~cm} \mathrm{~m}^{-2}$ for freshly prepared $\mathrm{Ni}$, and $4.99 \mathrm{~mA} \mathrm{~cm}^{-2}$ for $\mathrm{Pt} / \mathrm{C}$ catalyst (Fig. $3 \mathrm{c}$, Supplementary Table 2). By fitting Bulter-Volmer equation in the Tafel regions, similar values were obtained (Fig. 3d, Supplementary Table 2 and Methods). To further quantify the intrinsic HOR activity, the $j_{0}$ is renormalized by the electrochemical active surface area (ECSA; see "Methods", Supplementary Fig. 19 and Table 3 for 

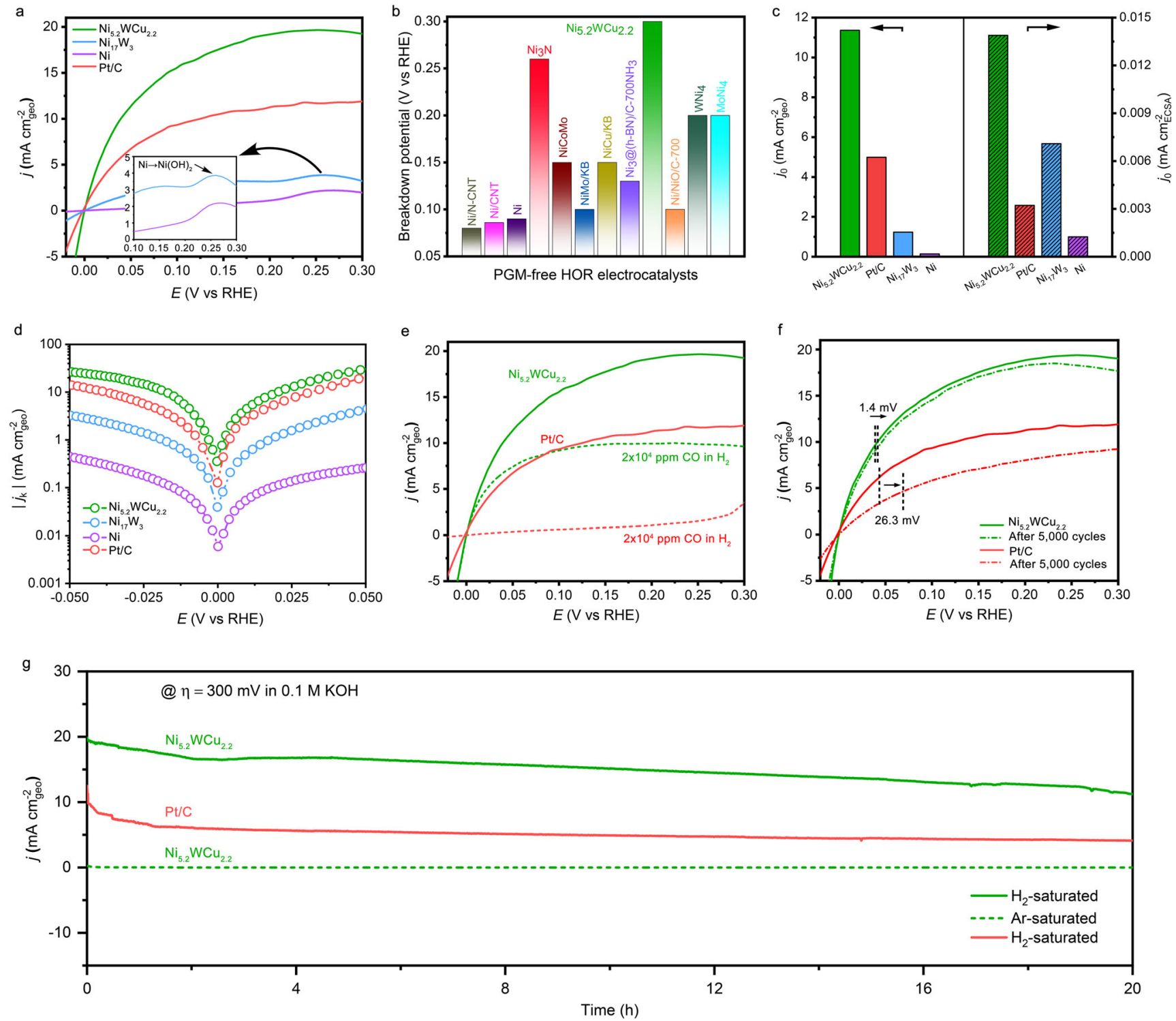

Fig. 3 Electrocatalytic HOR performances. a Polarization curves for the HOR on $\mathrm{Ni}_{5.2} \mathrm{WCu}_{2.2}, \mathrm{Ni}_{17} \mathrm{~W}_{3}, \mathrm{Ni}$, and commercial $\mathrm{Pt} / \mathrm{C}$ catalyst measured in $\mathrm{H}_{2-}$ saturated $0.1 \mathrm{M} \mathrm{KOH}$. Scan rate: $1 \mathrm{mV} \mathrm{s}^{-1}$. Inset shows $\mathrm{HOR}$ curves at high anode potentials, showing the surface oxidation of $\mathrm{Ni}_{17} \mathrm{~W}_{3}$ and $\mathrm{Ni}_{\text {catalysts. }}$ b Comparison of breakdown potential of $\mathrm{Ni}_{5.2} \mathrm{WCu}_{2.2}$ with various PGM-free HOR catalysts reported previously. Breakdown potential means HOR stops at this potential. c Comparison of exchange current density $\left(j_{0}\right)$ of various studied catalysts normalized by geometric areas (unpatterned) and ECSA (patterned), respectively. $\mathbf{d} \mathrm{HOR} / \mathrm{HER}$ Tafel plots of the kinetic current density on $\mathrm{Ni}_{5.2} \mathrm{WCu}_{2.2}, \mathrm{Ni}_{17} \mathrm{~W}_{3}, \mathrm{Ni}$, and $\mathrm{Pt} / \mathrm{C}$ in $\mathrm{H}_{2}$-saturated $0.1 \mathrm{M} \mathrm{KOH}$. e HOR polarization curves for $\mathrm{Ni}_{5.2} \mathrm{WCu}_{2.2}$ alloy and $\mathrm{Pt} / \mathrm{C}$ catalyst in $\mathrm{H}_{2}$-saturated $0.1 \mathrm{M} \mathrm{KOH}$ with (dashed lines) and without (solid lines) the presence of 20,000 ppm CO. $\mathbf{f} \mathrm{HOR}$ polarization curves for $\mathrm{Ni}_{5.2} \mathrm{WCu}_{2.2}$ alloy and $\mathrm{Pt} / \mathrm{C}$ catalyst before (solid lines) and after (dashed lines) accelerated durability test, respectively. The durability test was performed at room temperature in $\mathrm{H}_{2}$-saturated $0.1 \mathrm{M} \mathrm{KOH}$ with the cyclic potential sweeping between $-0.2 \mathrm{~V}$ to 0.2 $\mathrm{V}$ at a sweep rate of $200 \mathrm{mV} \mathrm{s}^{-1}$. $\mathbf{g}$ Chronoamperometry $\left(j-\mathrm{t}\right.$ ) responses recorded on $\mathrm{Ni}_{5.2} \mathrm{WCu}_{2.2}$ alloy and Pt/C catalyst at a $300 \mathrm{mV}$ overpotential in $\mathrm{H}_{2}$-saturated $0.1 \mathrm{M} \mathrm{KOH}$ at room temperature. Identical measurement on $\mathrm{Ni}_{5.2} \mathrm{WCu}_{2.2}$ alloy in Ar-saturated $0.1 \mathrm{M} \mathrm{KOH}$ was also carried out for comparison.

details), yielding a value of $0.014 \mathrm{~mA} \mathrm{~cm}{ }^{-2}$ for $\mathrm{Ni}_{5.2} \mathrm{WCu}_{2.2}$, which is 1.96 times higher than $\mathrm{Ni}_{17} \mathrm{~W}_{3}$ and 4.31 times higher than $\mathrm{Pt} / \mathrm{C}$ catalyst (Fig. 3c). We also carried out the feed ratio-, temperature-, and time-dependent control experiments and unveiled that the optimized HOR activity was obtained on Ni-W-Cu alloy that was synthesized with Ni:W atomic ratio of 4:1 and then annealed at $500^{\circ}$ C for $1 \mathrm{~h}$ (Supplementary Figs. 20-24).

We next report that our ternary $\mathrm{Ni}_{5.2} \mathrm{WCu}_{2.2}$ alloy shows good resistance to CO poisoning. It is well known that PGM catalysts (such as $\mathrm{Pt}$ ) are poisoned very rapidly in the presence of $\mathrm{CO}$ because of its preferential adsorption on Pt that blocks the active sites $^{45}$. In Fig. 3e, we find that the Pt/C catalyst loses HOR activity completely with 20,000 ppm CO in the $\mathrm{H}_{2}$ fuel. By stark contrast, the $\mathrm{Ni}_{5.2} \mathrm{WCu}_{2.2}$ catalyst can retain high HOR activity with the same level of CO contamination, exhibiting its remarkable COtolerant ability. Besides, our results further show that the HOR activity decreases on both $\mathrm{Ni}_{5.2} \mathrm{WCu}_{2.2}$ and $\mathrm{Pt} / \mathrm{C}$ catalysts when having 20,000 ppm $\mathrm{CO}_{2}$ in the $\mathrm{H}_{2}$ fuel (Supplementary Fig. 25). The detailed poison mechanism is unclear and needs further investigations.

Apart from activity and $\mathrm{CO}$ tolerance, another critical metric for the application of $\mathrm{Ni}_{52} \mathrm{WCu}_{2.2}$ alloy as a PGM-free anode is the long-term stability-especially the stability at high anode potentials. To assess this, we performed two sets of stability tests on our $\mathrm{Ni}_{5.2} \mathrm{WCu}_{2.2}$ alloy catalyst. We first performed accelerated durability tests (ADT) by applying linear potential sweeps between -0.2 and 

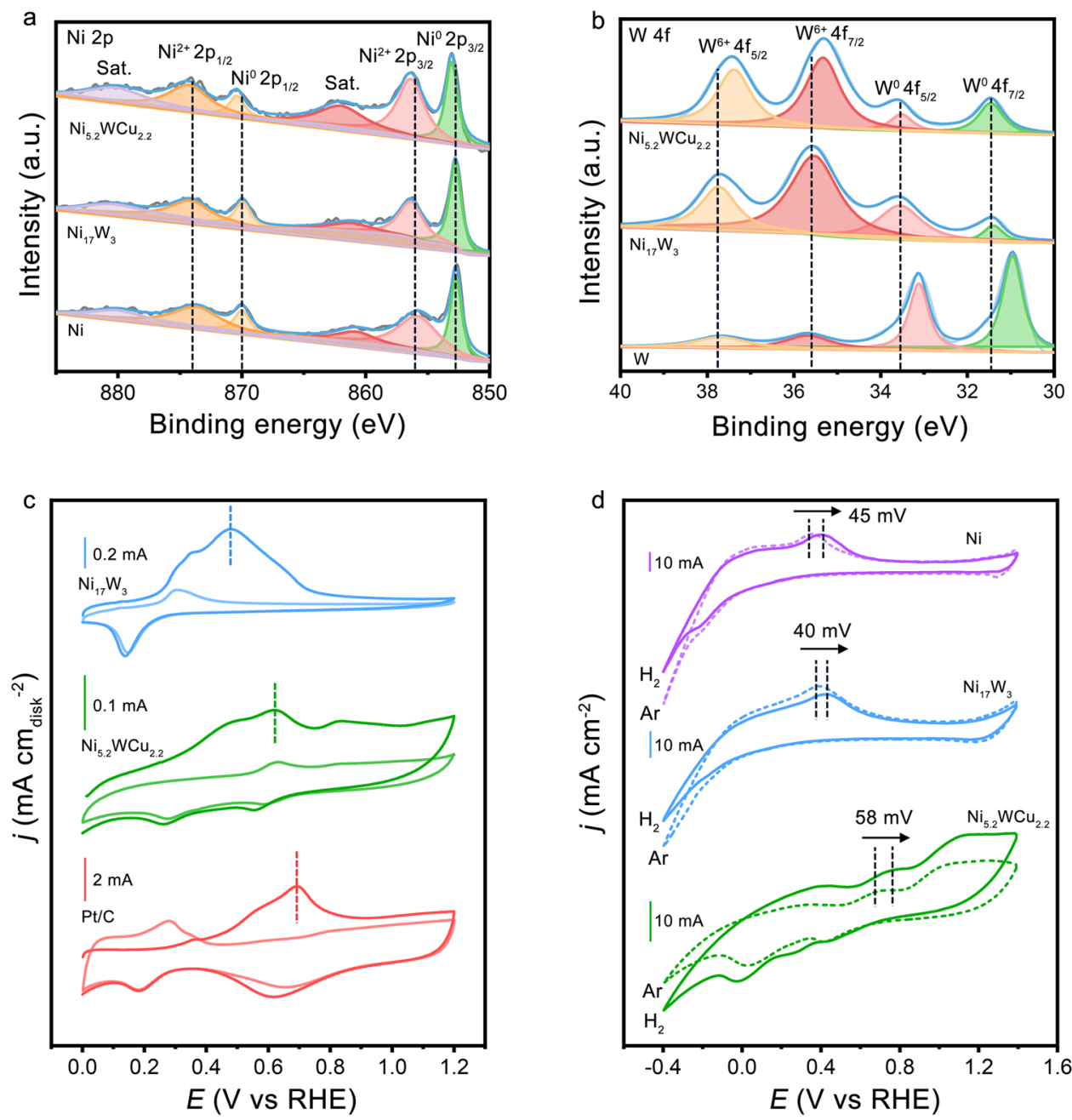

Fig. 4 Surface analysis of different catalysts. a $\mathrm{Ni} 2 p$ XPS spectra of $\mathrm{Ni}_{5.2} \mathrm{WCu}_{2.2}, \mathrm{Ni}_{17} \mathrm{~W}_{3}$, and Ni. b W $4 f X P S$ spectra of $\mathrm{Ni}_{5.2} \mathrm{WCu}_{2.2}, \mathrm{Ni}_{17} \mathrm{~W}_{3}$, and $\mathrm{W}$. c CO-stripping measurements on $\mathrm{Ni}_{5.2} \mathrm{WCu}_{2.2}, \mathrm{Ni}_{17} \mathrm{~W}_{3}$, and Pt/C catalyst in $0.1 \mathrm{M} \mathrm{KOH}$ electrolyte. Scan rate: $20 \mathrm{mV} \mathrm{s}^{-1}$. Rotation speed: 1600 r.p.m. The light-colored curves in c show the second cycle of the measurements. d CV curves of $\mathrm{Ni}_{5.2} \mathrm{WCu}_{2.2}, \mathrm{Ni}_{17} \mathrm{~W}_{3}$, and $\mathrm{Ni}$ in $\mathrm{H}_{2}-$ and $\mathrm{Ar}$-saturated $0.1 \mathrm{M} \mathrm{KOH}$, respectively. Scan rate: $50 \mathrm{mV} \mathrm{s}^{-1}$.

$0.2 \mathrm{~V}$ at $200 \mathrm{mV} \mathrm{s}^{-1}$ in $\mathrm{H}_{2}$-saturated $0.1 \mathrm{M} \mathrm{KOH}$ electrolyte. After 5,000 cycles, the $\mathrm{Ni}_{5.2} \mathrm{WCu}_{2.2}$ alloy shows a $1.4 \mathrm{mV}$ increase in halfwave potential, versus $26.3 \mathrm{mV}$ observed on Pt/C catalyst (Fig. 3f), implying that $\mathrm{Ni}_{5.2} \mathrm{WCu}_{2.2}$ alloy has stability better than $\mathrm{Pt} / \mathrm{C}$ catalyst. Then, we evaluated the ability of $\mathrm{Ni}_{5.2} \mathrm{WCu}_{2.2}$ alloy to continuously catalyze the HOR using chronoamperometry $(j \sim \mathrm{t})$ at a high anode potential of $0.3 \mathrm{~V}$ versus RHE. As shown in Fig. $3 \mathrm{~g}$, the current density $\left(\sim 20 \mathrm{~mA} \mathrm{~cm}^{-2}\right)$ generated from $\mathrm{Ni}_{5.2} \mathrm{WCu}_{2.2}$ decreases to $16.5 \mathrm{~mA} \mathrm{~cm}^{-2}$ after $2 \mathrm{~h}$, followed by slow degradation over the next $18 \mathrm{~h}$. This degradation was likely caused by selective W leaching (Supplementary Fig. 26). By contrast, Pt/C catalyst delivers a current density of mere $10 \mathrm{~mA} \mathrm{~cm}^{-2}$ at the beginning, which decreases progressively to about $4.3 \mathrm{~mA} \mathrm{~cm}^{-2}$ over a $20 \mathrm{~h}$ of operation. After aggressive stability tests, the crystal phase, structure and composition of the $\mathrm{Ni}_{5.2} \mathrm{WCu}_{2.2}$ alloy remained almost unchanged (Supplementary Figs. 27-29), whereas Pt/C catalyst suffered from agglomeration and even detachment of Pt nanoparticles (Supplementary Fig. 30). These results reveal superior HOR stability of $\mathrm{Ni}_{5.2} \mathrm{WCu}_{2.2}$ alloy compared with $\mathrm{Pt} / \mathrm{C}$ catalyst.

Surface structure and chemistry of catalyst. The formation of a ternary $\mathrm{Ni}_{5.2} \mathrm{WCu}_{2.2}$ alloy enables a HOR catalyst that shows high activity and stability at large anode potential, as well as good resistance to $\mathrm{CO}$ poisoning. In this section, we study the structural and chemical characters that affect and determine these performances. X-ray photoelectron spectroscopy (XPS) analysis of the studied samples showed that $\mathrm{Ni}, \mathrm{Ni}_{17} \mathrm{~W}_{3}$, and $\mathrm{Ni}_{5.2} \mathrm{WCu}_{2.2}$ are all metallic in nature with certain surface oxidation (Fig. $4 \mathrm{a}$ and $b$ ). We note that some degree of surface oxidation is nearly inevitable when these Ni-based compounds are exposed to air, analogous to our previous observation ${ }^{21}$. XPS measurements also revealed that the $\mathrm{Ni} 2 p$ binding energies of $\mathrm{Ni}_{5.2} \mathrm{WCu}_{2.2}$ shifted $0.3 \mathrm{eV}$ to higher energy with respect to $\mathrm{Ni}_{17} \mathrm{~W}_{3}$ (Fig. 4a). Meanwhile, the $\mathrm{W} 4 f \mathrm{XPS}$ of $\mathrm{Ni}_{5.2} \mathrm{WCu}_{2.2}$ showed a shift of the $\mathrm{W}$ core levels to lower binding energies compared with $\mathrm{Ni}_{17} \mathrm{~W}_{3}$ (Fig. 4b). These results indicated electron donation from $\mathrm{Ni}$ to $\mathrm{W}$ once $\mathrm{Cu}$ participate in the alloy, leading to modulated electronic structure. Our Bader analyses further confirm such charge redistribution after incorporating $\mathrm{Cu}$ into the alloy structure (Supplementary Fig. 31).

To further probe the surface features, we conducted $\mathrm{CO}$ stripping ( $\mathrm{CO}$ electrooxidation) experiments on $\mathrm{Ni}_{17} \mathrm{~W}_{3}$ and $\mathrm{Ni}_{5.2} \mathrm{WCu}_{2.2}$ with $\mathrm{Pt} / \mathrm{C}$ catalyst as a reference. Results shown in Fig. 4c display that the oxidation of adsorbed $\mathrm{CO}\left(\mathrm{CO}^{*}\right)$ occurs at $0.69 \mathrm{~V}$ for $\mathrm{Pt} / \mathrm{C}$ catalyst, which is in agreement with prior reports ${ }^{46}$. By contrast, $\mathrm{Ni}_{17} \mathrm{~W}_{3}$ oxidizes $\mathrm{CO}^{*}$ at a much lower potential of $0.48 \mathrm{~V}$, and $\mathrm{Ni}_{5.2} \mathrm{WCu}_{2.2}$ has a $\mathrm{CO}$-stripping peak 
located in the middle $(0.62 \mathrm{~V})$. These results indicate that both $\mathrm{Ni}_{17} \mathrm{~W}_{3}$ and $\mathrm{Ni}_{5.2} \mathrm{WCu}_{2.2}$ have a much lower $\mathrm{CO}$ adsorption ability compared with the $\mathrm{Pt} / \mathrm{C}$ catalyst, leading to the good COtolerance property observed in Fig. 3e. Moreover, in alkaline electrolytes, because the $\mathrm{OH}$ adsorption can facilitate the removal of the $\mathrm{CO}^{*}$ (ref. ${ }^{47}$ ), our CO-stripping results thus offer additional surface information that $\mathrm{Ni}_{17} \mathrm{~W}_{3}$ and $\mathrm{Ni}_{5.2} \mathrm{WCu}_{2.2}$ possess stronger $\mathrm{OH}$ adsorption than $\mathrm{Pt} / \mathrm{C}$ catalysts following the order of $\mathrm{Ni}_{17} \mathrm{~W}_{3}>\mathrm{Ni}_{5.2} \mathrm{WCu}_{2.2}>\mathrm{Pt} / \mathrm{C}$.

Surface analysis of the studied samples was also carried out using cyclic voltammetry in $0.1 \mathrm{M} \mathrm{KOH}$ electrolyte that saturated by $\mathrm{Ar}$ and $\mathrm{H}_{2}$, respectively. At a large sweep rate of $50 \mathrm{mV} \mathrm{s}^{-1}$, the oxidation curve of $\mathrm{Ni}_{5.2} \mathrm{WCu}_{2.2}$ appears at higher anode potential than that of $\mathrm{Ni}$ and $\mathrm{Ni}_{17} \mathrm{~W}_{3}$ (Fig. 4d), suggesting its superior oxidation-tolerant ability ${ }^{27}$. Intriguingly, we find that the oxidation peak of $\mathrm{Ni}_{5.2} \mathrm{WCu}_{2.2}$ in $\mathrm{H}_{2}$-saturated $0.1 \mathrm{M} \mathrm{KOH}$ exhibits a $58 \mathrm{mV}$ positive shift relative to that in Ar-saturated 0.1 M KOH (Fig. 4d). Similar positive shifts were also observed on $\mathrm{Ni}$ $(45 \mathrm{mV})$ and $\mathrm{Ni}_{17} \mathrm{~W}_{3}(40 \mathrm{mV})$ but with smaller values. The notable shift of oxidation peak in $\mathrm{H}_{2}$ - and Ar-saturated electrolytes likely result from the various degrees of $\mathrm{H}_{2}$ adsorbed on these Ni-based catalysts, which indicates that the adsorption of $\mathrm{H}_{2}$ decreases in the order of $\mathrm{Ni}_{17} \mathrm{~W}_{3}>\mathrm{Ni}>\mathrm{Ni}_{5.2} \mathrm{WCu}_{2.2}$.

Computational studies. With these experimental information in hand, we now turn to perform density functional theory (DFT) to gain fundamental insight into mechanisms responsible for the excellent activity and stability, as well as the good CO-tolerance
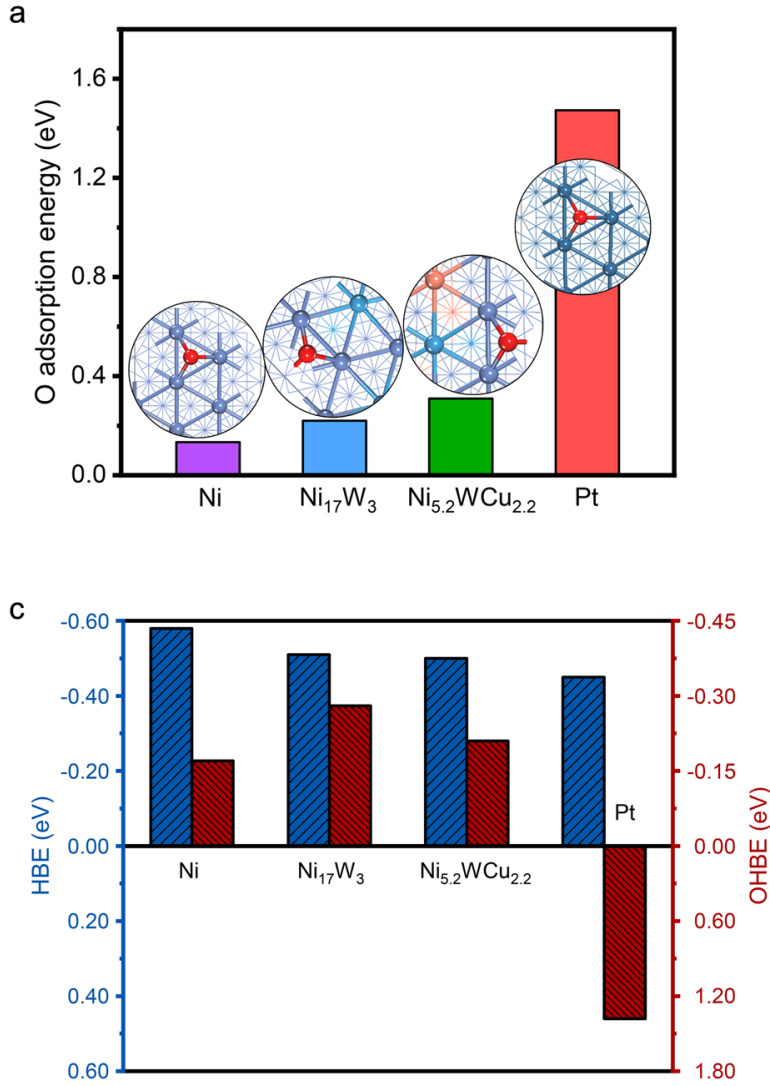

property (see Methods). We constructed and optimized crystal models of $\mathrm{Ni}_{5.2} \mathrm{WCu}_{2.2}(111), \mathrm{Ni}_{17} \mathrm{~W}_{3}(111), \mathrm{Ni}(111)$, and $\mathrm{Pt}(111)$ to represent the catalytic surfaces (see Methods; Supplementary Figs. 32-36). According to the DFT calculations, O-species prefer to adsorb on $\mathrm{Ni}(0.133 \mathrm{eV})$ and $\mathrm{Ni}_{17} \mathrm{~W}_{3}(0.22 \mathrm{eV})$, whereas such adsorption on $\mathrm{Ni}_{5.2} \mathrm{WCu}_{2.2}(0.31 \mathrm{eV})$ is considerably weak (Fig. 5a). These results predict that the oxidation of $\mathrm{Ni}_{5.2} \mathrm{WCu}_{2.2}$ is more difficult to occur as compared to $\mathrm{Ni}$ and $\mathrm{Ni}_{17} \mathrm{~W}_{3}$ (refs. ${ }^{48,49}$ ), consistent with our experimentally observed HOR stability at higher anode potential. Additionally, our DFT simulations reveal that $\mathrm{Pt}$ possesses a much higher $\mathrm{CO}$ adsorption strength $(-1.78 \mathrm{eV})$ than that of $\mathrm{Ni}_{17} \mathrm{~W}_{3}(-1.42 \mathrm{eV})$ and $\mathrm{Ni}_{5.2} \mathrm{WCu}_{2.2}(-1.55 \mathrm{eV})$ (Fig. 5b), which explain the marked COtolerance ability of $\mathrm{Ni}_{5.2} \mathrm{WCu}_{2.2}$ and agree well with above COstripping trend (Fig. 4c).

Although the HOR mechanism in alkaline electrolytes is still debated ${ }^{650-52}$, recent research has gradually led to agreement that hydrogen binding energy ( $\mathrm{HBE}$ ) and $\mathrm{OH}$ binding energy (OHBE)/oxophilicity both serve as descriptor for HOR performance ${ }^{27,50,53}$. With DFT calculations (Fig. 5c), we revealed that although the HBE of $\operatorname{Pt}(111)$ is optimum, whereas the adsorption energy of $\mathrm{OH}$ is too weak on $\mathrm{Pt}(111)$. As to $\mathrm{Ni}(111)$ facet, the HBE value is $-0.58 \mathrm{eV}$, which means a too strong $\mathrm{H}$ binding that hampers HOR catalysis, agreeing with previous study ${ }^{23}$. Our DFT results further show that ternary $\mathrm{Ni}_{5.2} \mathrm{WCu}_{2.2}$ alloy yields a HBE close to $\mathrm{Pt}(111)$; moreover, the hydroxyl adsorption on $\mathrm{Ni}_{5.2} \mathrm{WCu}_{2.2}(111)$ is significantly enhanced compared with $\mathrm{Pt}(111)$. Thus, this ternary-alloy-designed $\mathrm{Ni}_{5.2} \mathrm{WCu}_{2.2}$ gives rise to near-optimal $\mathrm{HBE}$ and OHBE that
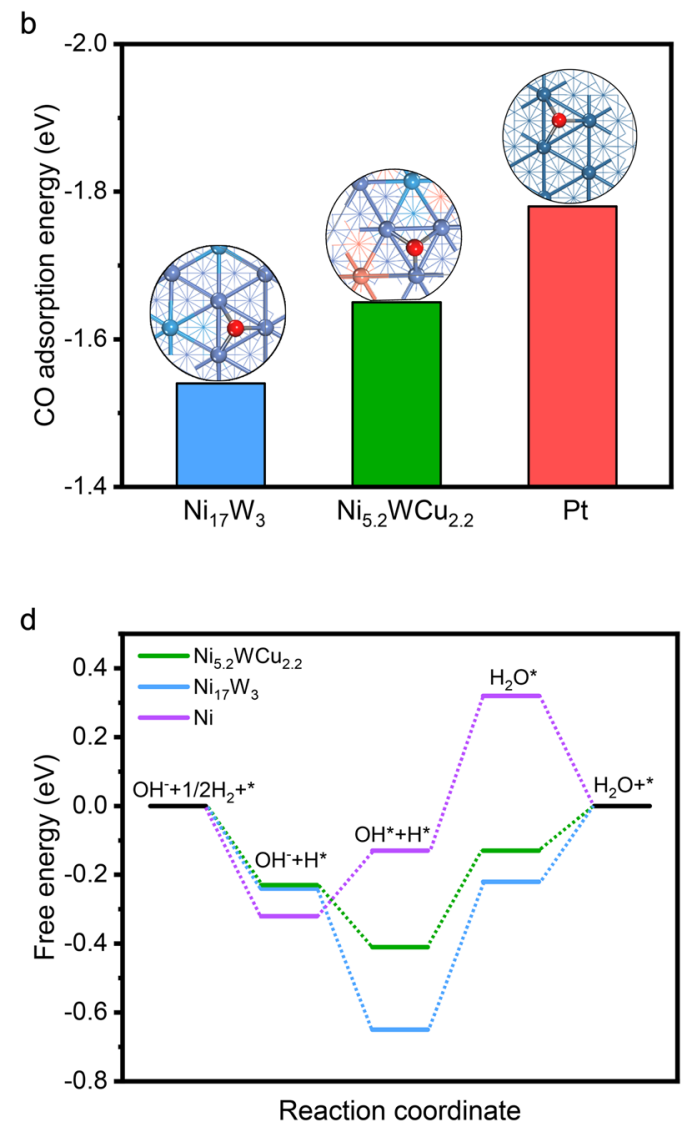

Fig. 5 DFT calculation. a $\mathrm{O}$ adsorption energy of $\mathrm{Ni}_{5.2} \mathrm{WCu}_{2.2}, \mathrm{Ni}_{17} \mathrm{~W}_{3}, \mathrm{Ni}$ and Pt. The more positive value indicates the better anti-oxidation ability. $\mathbf{b}$ CO adsorption energy of $\mathrm{Ni}_{5.2} \mathrm{WCu}_{2.2}, \mathrm{Ni}_{17} \mathrm{~W}_{3}$ and Pt. Insets in $\mathbf{a}$ and $\mathbf{b}$ presents corresponding catalyst models. Color labels: darkblue balls, Pt atoms; violet balls, $\mathrm{Ni}$ atoms; blue balls, W atoms; orange balls, $\mathrm{Cu}$; black balls, $\mathrm{C}$ atoms; red balls, $\mathrm{O}$ atoms. c HBEs and OHBEs of $\mathrm{Ni}_{5.2} \mathrm{WCu}_{2.2}, \mathrm{Ni}_{17} \mathrm{~W}_{3}, \mathrm{Ni}_{\text {and }} \mathrm{Pt}$. $\mathbf{d}$ Free energy diagrams for reaction pathways on $\mathrm{Ni}_{5.2} \mathrm{WCu}_{2.2}, \mathrm{Ni}_{17} \mathrm{~W}_{3}$ and $\mathrm{Ni}$ catalysts, respectively, revealing that the Volmer step is the rate-limiting step. 
promote the HOR kinetics. We also computed the HBE and OHBE of $\mathrm{Ni}_{17} \mathrm{~W}_{3}$ for comparison (Fig. 5c). Despite this catalyst exhibits stronger OHBE than $\mathrm{Pt}(111)$, its $\mathrm{HBE}$ is unfortunately strong, thus showing inferior HOR activity. The optimized HBE and OHBE that enabled by the synergy of $\mathrm{Ni}, \mathrm{W}$, and $\mathrm{Cu}$ in the ternary alloy can be further verified by our projected density of states (PDOS) analyses (Supplementary Fig. 37).

We note that our theoretically predicted trend of $\mathrm{OH}$ adsorption and $\mathrm{CO}$ adsorption perfectly match with $\mathrm{CO}$ stripping results (Fig. 4c). Moreover, the free energy diagrams that we computed for the reaction pathways on various catalysts are presented in Fig. 5d. Results show that both $\mathrm{H}$ and $\mathrm{OH}$ adsorptions on $\mathrm{Ni}_{17} \mathrm{~W}_{3}$ and $\mathrm{Ni}_{5.2} \mathrm{WCu}_{2.2}$ are exergonic, whereas the $\mathrm{H}_{2} \mathrm{O}$ formation and desorption steps on the two catalysts are endothermic. By contrast, $\mathrm{H}$ adsorption and $\mathrm{H}_{2} \mathrm{O}$ desorption on $\mathrm{Ni}$ are exergonic, but $\mathrm{OH}$ adsorption and $\mathrm{H}_{2} \mathrm{O}$ formation on $\mathrm{Ni}$ are endothermic. Our calculations thus predict that $\mathrm{H}_{2} \mathrm{O}$ formation (i.e., Volmer step) is the rate-determining step, showing energy barriers of $0.45,0.43$, and $0.28 \mathrm{eV}$ for the $\mathrm{Ni}$, $\mathrm{Ni}_{17} \mathrm{~W}_{3}$ and $\mathrm{Ni}_{5.2} \mathrm{WCu}_{2.2}$ catalysts, respectively. The much lower energy barrier obtained on $\mathrm{Ni}_{5.2} \mathrm{WCu}_{2.2}$ contributes to its exceptional HOR performance. Altogether, our experimental and computational studies reveal that the synergy among $\mathrm{Ni}, \mathrm{W}$, and $\mathrm{Cu}-\mathrm{a}$ multiple-element alloying effect-enables the optimized HBE and OHBE that improve the energetics for HOR, as well as the wide stability window up to $0.3 \mathrm{~V}$ versus RHE.

\section{Discussion}

To conclude, this work demonstrates a multiple-element $\mathrm{Ni}$ based alloy strategy for creating HOR catalyst that makes use of earth-abundant elements, showing exceptional activity and stability in alkaline electrolyte. This notable HOR performance can be explained by the alloying effect among nickel, tungsten and copper, which work in synergy to enable optimized hydrogen and hydroxyl bindings, as well as the improved resistance against surface oxidation. Our study calls for further exploration of multiple-element alloys composed of other cheap metals, thereby aiding the development of more efficient HOR catalysts for AEMFC anodes.

\section{Methods}

Synthesis of $\mathrm{Cu}(\mathrm{OH})_{2}$ nanowires on $\mathrm{Cu}$ foam. The $\mathrm{Cu}(\mathrm{OH})_{2}$ NWs were grown on commercial $\mathrm{Cu}$ foam via a simple anodization method. Prior to the growth of nanowires, a piece of $\mathrm{Cu}$ foam $(1 \mathrm{~cm} \times 3 \mathrm{~cm})$ was ultrasonically cleaned by hydrochloric acid solution, ethanol and deionized water, respectively, which was then immersed into a two-electrode system using Pt foil as the counter electrode in $1 \mathrm{M} \mathrm{NaOH}$ solution. The anodization was carried out at a constant current of 60 $\mathrm{mA}$ for 20 min to obtain $\mathrm{Cu}(\mathrm{OH})_{2}$ nanowires on $\mathrm{Cu}$ foam.

Synthesis of $\mathbf{N i}_{\mathbf{5 . 2}} \mathbf{W} \mathbf{C u}_{\mathbf{2 . 2}}, \mathbf{N i}_{\mathbf{1}} \mathbf{W} \mathbf{\mathbf { 3 }}$ and $\mathbf{N i}$. Firstly, $\mathrm{Ni}\left(\mathrm{NO}_{3}\right)_{2} \cdot 6 \mathrm{H}_{2} \mathrm{O}(581.6 \mathrm{mg})$, $\left(\mathrm{NH}_{4}\right)_{6} \mathrm{H}_{2} \mathrm{~W}_{12} \mathrm{O}_{40} \cdot \mathrm{xH}_{2} \mathrm{O}(123.2 \mathrm{mg})$ and $\mathrm{CO}\left(\mathrm{NH}_{2}\right)_{2}(360.4 \mathrm{mg})$ were dissolved in $30 \mathrm{~mL}$ deionized water, and then transferred into a $50 \mathrm{~mL}$ Teflon-lined stainlesssteel autoclave. The as-synthesized indigo $\mathrm{Cu}(\mathrm{OH})_{2} \mathrm{NWs}$ on $\mathrm{Cu}$ foam was immersed into the solution and placed against the wall of autoclave. Subsequently, the autoclave was maintained at $130^{\circ} \mathrm{C}$ for $8 \mathrm{~h}$. The foam was taken out and washed by deionized water several times to obtain $\mathrm{NiW}-\mathrm{Cu}(\mathrm{OH})_{2} \mathrm{NWs}$ precursor. Finally, the precursor was annealed at $500{ }^{\circ} \mathrm{C}$ for $1 \mathrm{~h}$ with a heating rate of $5{ }^{\circ} \mathrm{C}$ under $5 \% \mathrm{H}_{2} / \mathrm{Ar}$ atmosphere to obtain $\mathrm{Ni}_{5.2} \mathrm{WCu}_{2.2}$ alloys. The mass loading of $\mathrm{Ni}_{5.2} \mathrm{WCu}_{2.2}$ alloys was $\sim 9.2 \mathrm{mg} \mathrm{cm}^{-2}$ as determined by weighing the mass of $\mathrm{Cu}$ foam before anodization and after the annealing process.

By comparison, $\mathrm{Ni}_{17} \mathrm{~W}_{3}$ and $\mathrm{Ni}$ precursors were directly grown on a clean $\mathrm{Ni}$ foam $(1 \mathrm{~cm} \times 3 \mathrm{~cm})$ that was not anodized in prior. To obtain NiW precursors, $\mathrm{Ni}$ $\left(\mathrm{NO}_{3}\right)_{2} \cdot 6 \mathrm{H}_{2} \mathrm{O}(581.6 \mathrm{mg}),\left(\mathrm{NH}_{4}\right)_{6} \mathrm{H}_{2} \mathrm{~W}_{12} \mathrm{O}_{40} \cdot \mathrm{xH}_{2} \mathrm{O}(123.2 \mathrm{mg})$ and $\mathrm{CO}\left(\mathrm{NH}_{2}\right)_{2}$ $(360.4 \mathrm{mg}$ ) were dissolved in $30 \mathrm{~mL}$ deionized water, and then transferred into a 50 $\mathrm{mL}$ Teflon-lined stainless-steel autoclave. The pure $\mathrm{Ni}$ foam was immersed into the solution and placed against the wall of autoclave. The Ni precursors were obtained under the same conditions without the addition of $\left(\mathrm{NH}_{4}\right)_{6} \mathrm{H}_{2} \mathrm{~W}_{12} \mathrm{O}_{40} \cdot \mathrm{xH}_{2} \mathrm{O}$. The hydrothermal process was all performed under $130^{\circ} \mathrm{C}$ for $8 \mathrm{~h}$. Then the foam was taken out and washed by deionized water several times followed by an annealing process at $500{ }^{\circ} \mathrm{C}$ for $1 \mathrm{~h}$ with a heating rate of $5{ }^{\circ} \mathrm{C}$ under $5 \% \mathrm{H}_{2} / \mathrm{Ar}$ atmosphere to obtain $\mathrm{Ni}_{17} \mathrm{~W}_{3}$ and $\mathrm{Ni}$ nanoparticles.
Material characterizations. The obtained samples were examined by multiple analytic techniques. Optical microscope images were obtained with a polarizing microscope (Leica DM2700P, Germany) equipped with a Leica MC190 HD camera. The morphology of the samples was determined by SEM (Zersss Supra 40) and TEM (JEOL 2010F(s)). The STEM and HRTEM images, and EDX elemental mappings were taken on JEMARM $200 \mathrm{~F}$ Atomic Resolution Analytical Microscope with an acceleration voltage of $200 \mathrm{kV}$. The KPFM characterization was carried out with Atom Force Microscope (Dimension Icon). ICP-AES data was obtained by an Optima 7300 DV instrument. XRD was performed on a Japan Rigaku DMax- $\gamma \mathrm{A}$ X-ray diffractometer with $\mathrm{Cu}$ Ka radiation $(\lambda=1.54178 \AA$ ). XPS was taken on an X-ray photoelectron spectrometer (ESCALab MKII) with an X-ray source $(\mathrm{Mg} \mathrm{Ka} h v=1253.6 \mathrm{eV})$.

XAFS measurements. The XAFS spectra (Ni K-edge) were collected at 1W1B station in Beijing Synchrotron Radiation Facility (BSRF). The storage rings of BSRF were operated at $2.5 \mathrm{GeV}$ with an average current of $250 \mathrm{~mA}$. Using Si(111) double-crystal monochromator, the data collection was carried out in transmission/fluorescence mode using ionization chamber. All spectra were collected in ambient conditions. The $k^{3}$-weighted EXAFS spectra were obtained by subtracting the post-edge background from the overall absorption and then normalizing with respect to the edge-jump step. Subsequently, $k^{3}$-weighted $\chi(k)$ data of Ni K-edge were Fourier transformed to real $(R)$ space using a hanning windows ( $\mathrm{d} k=1.0 \AA^{-1}$ ) to separate the EXAFS contributions from different coordination shells. To obtain the quantitative structural parameters around central atoms, least-squares curve parameter fitting was performed using the ARTEMIS module of IFEFFIT software packages ${ }^{54}$.

Electrochemical measurements. A standard three-electrode set-up was applied to perform the HOR electrochemical measurements on the VSP-300 Potentiostat (Bio-Logic, France). Carbon rod was used as the counter electrode and all potentials were measured against an $\mathrm{Ag} / \mathrm{AgCl}$ reference electrode (saturated in $3.0 \mathrm{M}$ $\mathrm{KCl})$ and converted to the RHE reference scale using following equation:

$$
\mathrm{E}(\text { vs. } \mathrm{RHE})=E(\text { vs. } \mathrm{Ag} / \mathrm{AgCl})+0.197+(0.059 \times \mathrm{pH})
$$

The as-synthesized $\mathrm{Ni}_{5.2} \mathrm{WCu}_{2.2}, \mathrm{Ni}_{17} \mathrm{~W}_{3}$ and $\mathrm{Ni}$ catalysts on $\mathrm{Cu}$ foam were directly used as working electrodes. After the annealing process, they were cut into $1 \mathrm{~cm} \times 1 \mathrm{~cm}$ pieces for electrochemical tests. The commercial $\mathrm{Pt} / \mathrm{C}$ was coated on a pure $\mathrm{Cu}$ foam $(1$ $\mathrm{cm} \times 1 \mathrm{~cm}$ ) with optimized loading of $1.5 \mathrm{mg} \mathrm{cm}^{-2}$ (Supplementary Fig. 38). Before HOR measurements, the electrolyte $(0.1 \mathrm{M} \mathrm{KOH})$ was bubbled with $\mathrm{H}_{2}$ gas for at least $30 \mathrm{~min}$. The EIS measurement was performed at $30 \mathrm{mV}$ overpotential and an amplitude of the sinusoidal voltage of $5 \mathrm{mV}$ (frequency range: $100 \mathrm{kHz}$ to $40 \mathrm{mHz}$ ). All the linear sweep voltammetry (LSV), cyclic voltammetry (CV), and chronoamperometry (CA) curves were $i R$-corrected.

The exchange current density $\left(j_{0}\right)$ can be obtained by fitting kinetic current density $\left(j_{\mathrm{k}}\right)$ versus the overpotential $(\eta)$ using the following Butler-Volmer equation:

$$
\mathrm{j}_{\mathrm{k}}=\mathrm{j}_{0}\left(e^{\frac{\alpha \mathrm{F}}{\mathrm{RT} \eta}}-e^{\frac{-(1-\alpha) \mathrm{F}}{\mathrm{RT}} \eta}\right)
$$

where $\alpha$ is the charge transfer coefficient, $\eta$ is the overpotential, $R$ is the ideal gas constant $\left(8.314 \mathrm{~J} \mathrm{~mol}^{-1} \mathrm{~K}^{-1}\right), T$ is the experimental temperature (298 $\mathrm{K}$ ), and $F$ is the Faraday's constant $\left(96,485 \mathrm{C} \mathrm{mol}^{-1}\right)$.

$\mathrm{CO}$ stripping was performed by holding the electrode potential at $0.1 \mathrm{~V}$ versus RHE for $10 \mathrm{~min}$ in the purged $\mathrm{CO}$ to adsorb $\mathrm{CO}$ on the metal surface, followed by Ar purging for another $30 \mathrm{~min}$ to remove residual $\mathrm{CO}$ in the electrolyte. The CO stripping current was obtained via cyclic voltammetry in a potential region from 0 to $1.2 \mathrm{~V}$ at a sweep rate of $20 \mathrm{mV} \mathrm{s}^{-1}$.

DFT calculations. We carried out DFT calculations using the Vienna ab initio simulation package (VASP) ${ }^{55,56}$ program with projector augmented wave $(\mathrm{PAW})^{57,58}$ method. The Perdew-Burke-Ernzerhof $(\mathrm{PBE})^{59}$ generalized gradient approximation (GGA) exchange-correlation functional was used throughout. A $500 \mathrm{eV}$ plane-wave kinetic energy cutoff was chosen, and a $5 \times 5 \times 1$ MonhorstPack k-point sampling was adopted for the structure relaxation. The convergence criterion for the electronic self-consistent iteration was set to be $10^{-4} \mathrm{eV}$. A residual force threshold of $0.02 \mathrm{eV}^{-1}$ was set for geometry optimizations. The calculations were conducted on (111) surface of $\mathrm{Ni}, \mathrm{Ni}_{17} \mathrm{~W}_{3}, \mathrm{Ni}_{5.2} \mathrm{WCu}_{2.2}$, and $\mathrm{Pt}$ models. Hubbard $U$ corrections were applied to transition metal d-electrons and the values of $U-J$ parameters for $\mathrm{Ni}(3.80), \mathrm{W}(6.20)$ and $\mathrm{Cu}$ (3.08) atoms were taken from the references ${ }^{60-62}$. The vacuum layer was set to be $15 \AA$ to ensure the separation between slabs.

The key reaction steps in alkaline HOR:

$$
\begin{gathered}
\mathrm{H}_{2}+\mathrm{OH}^{-}+{ }^{*} \rightarrow{ }^{*} \mathrm{H}+\mathrm{H}_{2} \mathrm{O}+\mathrm{e}^{-} \\
{ }^{*} \mathrm{H}+\mathrm{OH}^{-} \rightarrow{ }^{*} \mathrm{H}+{ }^{*} \mathrm{OH}+\mathrm{e}^{-} \\
{ }^{*} \mathrm{H}+{ }^{*} \mathrm{OH} \rightarrow{ }^{*} \mathrm{H}_{2} \mathrm{O} \\
{ }^{*} \mathrm{H}_{2} \mathrm{O} \rightarrow{ }^{*}+\mathrm{H}_{2} \mathrm{O}
\end{gathered}
$$


The Gibbs free energy changes are calculated as follows:

$$
\begin{gathered}
\Delta G_{1}=G\left({ }^{*} \mathrm{H}\right)+G\left(\mathrm{H}_{2} \mathrm{O}\right)-G\left({ }^{*}\right)-G\left(\mathrm{OH}^{-}\right)-G\left(\mathrm{H}_{2}\right) \\
\triangle G_{2}=G\left({ }^{*} \mathrm{OH}-{ }^{*} \mathrm{H}\right)-G\left({ }^{*} \mathrm{H}\right)-G\left(\mathrm{OH}^{-}\right) \\
\triangle G_{3}=G\left({ }^{*} \mathrm{H}_{2} \mathrm{O}\right)-G\left({ }^{*} \mathrm{OH}-{ }^{*} \mathrm{H}\right) \\
\triangle G_{4}=G\left({ }^{*}\right)+G\left(\mathrm{H}_{2} \mathrm{O}\right)-G\left({ }^{*} \mathrm{H}_{2} \mathrm{O}\right)
\end{gathered}
$$

The $G$ values are calculated by:

$$
G=H-T \Delta S=E_{\mathrm{DFT}}+E_{\mathrm{ZPE}}-\mathrm{TS}
$$

$E_{\mathrm{DFT}}$ is the total energy from the DFT calculation. $E_{\mathrm{ZPE}}$ is the zero-point energy, $S$ is the entropy and $T$ is the temperature $(298 \mathrm{~K})$.

The adsorption energies $\left(\Delta E_{\mathrm{ad}}\right)$ for $\mathrm{O}$ and $\mathrm{CO}$ were calculated by the following equations:

The $\mathrm{O}$ adsorption energies were calculated by:

$$
\Delta E_{\mathrm{O}-\text { ad }}=E_{\mathrm{O} @ \text { cat. }}-E_{\text {cat }}-E_{\mathrm{O}}
$$

The $\mathrm{CO}$ adsorption energies were calculated by:

$$
\Delta E_{\mathrm{CO}-\mathrm{ad}}=E_{\mathrm{CO} @_{\text {cat. }}}-E_{\text {cat }}-E_{\mathrm{CO}}
$$

The HBE and OHBE can be calculated by following equations:

The HBE were calculated by:

The OHBE were calculated by:

$$
\mathrm{HBE}=E_{\mathrm{H} @ \mathrm{cat} .}-E_{\text {cat }}-E_{\mathrm{H}}
$$

$$
\mathrm{OHBE}=E_{\mathrm{OH} @ \text { cat. }}-E_{\text {cat }}-E_{\mathrm{OH}}
$$

Note: $E_{\mathrm{O} @ \text { cat. }}, E_{\mathrm{CO} @ \text { cat, }}, E_{\mathrm{H} @ \mathrm{cat},}$ and $E_{\mathrm{OH} @ \text { cat. }}$ represent the energies of metals or alloy slabs with the adsorbed $\mathrm{O}, \mathrm{CO}, \mathrm{H}$, and $\mathrm{OH}$ species; the $E_{\text {cat, }}, E_{\mathrm{O}}, E_{\mathrm{CO}}, E_{\mathrm{H}}$, and $E_{\mathrm{OH}}$ represent the energies of the metals or alloys slabs, the $\mathrm{O}$ atoms, the $\mathrm{CO}$ species, the $\mathrm{H}$ atoms, and $\mathrm{OH}$ species, respectively. Since the ground state of $\mathrm{O}_{2}$ molecule is poorly described by DFT calculations, we thus used gas-phase $\mathrm{H}_{2} \mathrm{O}$ and $\mathrm{H}_{2}$ as references to calculate the $E_{\mathrm{O}}\left(E_{\mathrm{O}}=E_{\mathrm{H} 2 \mathrm{O}}-E_{\mathrm{H} 2}\right)$. As to the $\mathrm{E}_{\mathrm{OH}}$, it can be obtained by $E_{\mathrm{OH}}=E_{\mathrm{H} 2 \mathrm{O}}-1 / 2 E_{\mathrm{H} 2}$. We calculated the Gibbs free energy changes of $G\left(\mathrm{OH}^{-}\right), G\left(\mathrm{H}_{2}\right)$ and $G\left(\mathrm{H}_{2} \mathrm{O}\right)$ according to a recent literature ${ }^{63}$.

\section{Data availability}

All experimental data within the article and its Supplementary Information are available from the corresponding author upon reasonable request.

Received: 23 December 2020; Accepted: 9 April 2021;

Published online: 11 May 2021

\section{References}

1. Yoshida, T. \& Kojima, K. Toyota MIRAI fuel cell vehicle and progress toward a future hydrogen society. Interface Mag. 24, 45-49 (2015).

2. Setzler, B. P., Zhuang, Z., Wittkopf, J. A. \& Yan, Y. Activity targets for nanostructured platinum-group-metal-free catalysts in hydroxide exchange membrane fuel cells. Nat. Nanotechnol. 11, 1020-1025 (2016).

3. Ott, S. et al. Ionomer distribution control in porous carbon-supported catalyst layers for high-power and low Pt-loaded proton exchange membrane fuel cells. Nat. Mater. 19, 77-85 (2020).

4. Garsany, Y., Atkinson, R. W., Gould, B. D. \& Swider-Lyons, K. E. High power, Low-Pt membrane electrode assemblies for proton exchange membrane fuel cells. J. Power Sources 408, 38-45 (2018).

5. Ohma, A. et al. Analysis of proton exchange membrane fuel cell catalyst layers for reduction of platinum loading at Nissan. Electrochim. Acta 56, 10832-10841 (2011).

6. Strmcnik, D. et al. Improving the hydrogen oxidation reaction rate by promotion of hydroxyl adsorption. Nat. Chem. 5, 300-306 (2013).

7. Wang, Y. et al. Synergistic Mn-Co catalyst outperforms Pt on high-rate oxygen reduction for alkaline polymer electrolyte fuel cells. Nat. Commun. 10, 1506 (2019).

8. Liang, $\mathrm{Y}$. et al. $\mathrm{Co}_{3} \mathrm{O}_{4}$ nanocrystals on graphene as a synergistic catalyst for oxygen reduction reaction. Nat. Mater. 10, 780-786 (2011).

9. Suntivich, J. et al. Design principles for oxygen-reduction activity on perovskite oxide catalysts for fuel cells and metal-air batteries. Nat. Chem. 3 , 546-550 (2011).

10. Dekel, D. R. Review of cell performance in anion exchange membrane fuel cells. J. Power Sources 375, 158-169 (2018).

11. Sheng, W., Gasteiger, H. A. \& Shao-Horn, Y. Hydrogen oxidation and evolution reaction kinetics on platinum: acid vs alkaline electrolytes. $J$. Electrochem. Soc. 157, B1529-B1536 (2010).
12. Durst, J. et al. New insights into the electrochemical hydrogen oxidation and evolution reaction mechanism. Energy Environ. Sci. 7, 2255-2260 (2014).

13. Zhuang, Z. et al. Nickel supported on nitrogen-doped carbon nanotubes as hydrogen oxidation reaction catalyst in alkaline electrolyte. Nat. Commun. 7, 10141 (2016)

14. Gottesfeld, S. et al. Anion exchange membrane fuel cells: current status and remaining challenges. J. Power Sources 375, 170-184 (2018).

15. Davydova, E. S., Mukerjee, S., Jaouen, F. \& Dekel, D. R. Electrocatalysts for hydrogen oxidation reaction in alkaline electrolytes. ACS Catal. 8, 6665-6690 (2018).

16. Oshchepkov, A. G., Braesch, G., Bonnefont, A., Savinova, E. R. \& Chatenet, M. Recent advances in the understanding of nickel-based catalysts for the oxidation of hydrogen-containing fuels in alkaline media. ACS Catal. 10, 7043-7068 (2020).

17. Mund, K., Richter, G. \& von Sturm, F. Titanium-containing raney nickel catalyst for hydrogen electrodes in alkaline fuel cell systems. J. Electrochem. Soc. 124, 1-6 (1977).

18. Kenjo, T. Doping effects of transition metals on the polarization characteristics in raney nickel hydrogen electrodes. Electrochim. Acta 33, $41-46$ (1988)

19. Kiros, Y., Majari, M. \& Nissinen, T. A. Effect and characterization of dopants to Raney nickel for hydrogen oxidation. J. Alloy. Compd. 360, 279-285 (2003).

20. Sheng, W. et al. Non-precious metal electrocatalysts with high activity for hydrogen oxidation reaction in alkaline electrolytes. Energy Environ. Sci. 7, 1719-1724 (2014)

21. Duan, Y. et al. Bimetallic nickel-molybdenum/tungsten nanoalloys for highefficiency hydrogen oxidation catalysis in alkaline electrolytes. Nat. Commun. 11, 4789 (2020).

22. Kabir, S. et al. Platinum group metal-free NiMo hydrogen oxidation catalysts: high performance and durability in alkaline exchange membrane fuel cells. $J$. Mater. Chem. A 5, 24433-24443 (2017).

23. Yang, Y. et al. Enhanced electrocatalytic hydrogen oxidation on $\mathrm{Ni} / \mathrm{NiO} / \mathrm{C}$ derived from a Nickel-based metal-organic framework. Angew. Chem. Int. Ed. 58, 10644-10649 (2019)

24. Yang, F. et al. Boosting hydrogen oxidation activity of $\mathrm{Ni}$ in alkaline media through oxygen-vacancy-rich $\mathrm{CeO}_{2} / \mathrm{Ni}$ heterostructures. Angew. Chem. Int. Ed. 58, 14179-14183 (2019).

25. Lu, S., Pan, J., Huang, A., Zhuang, L. \& Lu, J. Alkaline polymer electrolyte fuel cells completely free from noble metal catalysts. Proc. Natl Acad. Sci. USA 105 20611 (2008).

26. Wang, T. et al. Weakening hydrogen adsorption on nickel via interstitial nitrogen doping promotes bifunctional hydrogen electrocatalysis in alkaline solution. Energy Environ. Sci. 12, 3522-3529 (2019).

27. $\mathrm{Ni}, \mathrm{W}$. et al. $\mathrm{Ni}_{3} \mathrm{~N}$ as an active hydrogen oxidation reaction catalyst in alkaline medium. Angew. Chem. Int. Ed. 58, 7445-7449 (2019).

28. Davydova, E. S., Speck, F. D., Paul, M. T. Y., Dekel, D. R. \& Cherevko, S. Stability limits of Ni-based hydrogen oxidation electrocatalysts for anion exchange membrane fuel cells. ACS Catal. 9, 6837-6845 (2019)

29. Mao, J. et al. Design of ultrathin Pt-Mo-Ni nanowire catalysts for ethanol electrooxidation. Sci. Adv. 3, el603068 (2017).

30. Gao, L. et al. Unconventional p-d hybridization interaction in PtGa ultrathin nanowires boosts oxygen reduction electrocatalysis. J. Am. Chem. Soc. 141 , 18083-18090 (2019).

31. Huang, X. et al. High-performance transition metal-doped $\mathrm{Pt}_{3} \mathrm{Ni}$ octahedra for oxygen reduction reaction. Science 348, 1230 (2015).

32. Escudero-Escribano, M. et al. Tuning the activity of Pt alloy electrocatalysts by means of the lanthanide contraction. Science 352, 73 (2016).

33. Qiu, Y. et al. BCC-phased $\mathrm{PdCu}$ alloy as a highly active electrocatalyst for hydrogen oxidation in alkaline electrolytes. J. Am. Chem. Soc. 140, 16580-16588 (2018).

34. Alia, S. M., Pivovar, B. S. \& Yan, Y. Platinum-coated copper nanowires with high activity for hydrogen oxidation reaction in base. J. Am. Chem. Soc. $\mathbf{1 3 5}$, 13473-13478 (2013)

35. Wang, H. \& Abruña, H. D. IrPdRu/C as $\mathrm{H}_{2}$ oxidation catalysts for alkaline fuel cells. J. Am. Chem. Soc. 139, 6807-6810 (2017).

36. Wang, H. \& Abruña, H. D. Rh and Rh alloy nanoparticles as highly active $\mathrm{H}_{2}$ oxidation catalysts for alkaline fuel cells. ACS Catal. 9, 5057-5062 (2019).

37. Wang, Y. et al. Pt-Ru catalyzed hydrogen oxidation in alkaline media: oxophilic effect or electronic effect? Energy Environ. Sci. 8, 177-181 (2015).

38. Cheon, J. Y. et al. Intrinsic relationship between enhanced oxygen reduction reaction activity and nanoscale work function of doped carbons. J. Am. Chem. Soc. 136, 8875-8878 (2014)

39. Fernández Garrillo, P. A., Grévin, B. \& Chevalier, N. \& Borowik, Ł. Calibrated work function mapping by Kelvin probe force microscopy. Rev. Sci. Instrum. 89, 043702 (2018).

40. Gao, F.-Y. et al. High.-curvature Transit.-Met. chalcogenide Nanostruct. a pronounced proximity Eff. enable fast selective $\mathrm{CO} 2$ electroreduction. Angew. Chem. Int. Ed. 55, 8706-8712 (2019). 
41. Shan, J. et al. $\mathrm{NiCu}$ single atom alloys catalyze the $\mathrm{CH}$ bond activation in the selective non- oxidative ethanol dehydrogenation reaction. Appl. Catal., BEnviron. 226, 534-543 (2018).

42. Zhang, T. et al. Atomically dispersed nickel(I) on an alloy-encapsulated nitrogen-doped carbon nanotube array for high-performance electrochemical $\mathrm{CO}_{2}$ reduction reaction. Angew. Chem. Int. Ed. 59, 12055-12061 (2020).

43. Zheng, J., Yan, Y. \& Xu, B. Correcting the hydrogen diffusion limitation in rotating disk electrode measurements of hydrogen evolution reaction kinetics. J. Electrochem. Soc. 162, F1470-F1481 (2015).

44. Oshchepkov, A. G. et al. Nanostructured nickel nanoparticles supported on vulcan carbon as a highly active catalyst for the hydrogen oxidation reaction in alkaline media. J. Power Sources 402, 447-452 (2018).

45. Valdés-López, V. F., Mason, T., Shearing, P. R. \& Brett, D. J. L. Carbon monoxide poisoning and mitigation strategies for polymer electrolyte membrane fuel cells-A review. Prog. Energy Combust. Sci. 79, 100842 (2020).

46. Li, J. et al. Experimental proof of the bifunctional mechanism for the hydrogen oxidation in alkaline media. Angew. Chem. Int. Ed. 56, 15594-15598 (2017).

47. Zhang, Z.-C. et al. Engineering phase and surface composition of $\mathrm{Pt}_{3} \mathrm{Co}$ nanocatalysts: A strategy for enhancing $\mathrm{CO}$ tolerance. Nano Energy 34, 224-232 (2017).

48. Dou, Y. et al. Approaching the activity limit of $\mathrm{CoSe}_{2}$ for oxygen evolution via Fe doping and Co vacancy. Nat. Commun. 11, 1664 (2020).

49. Siahrostami, S. et al. Enabling direct $\mathrm{H}_{2} \mathrm{O}_{2}$ production through rational electrocatalyst design. Nat. Mater. 12, 1137-1143 (2013).

50. Davydova, S. E., Zaffran, J., Dhaka, K., Toroker, C. M. \& Dekel, R. D. Hydrogen oxidation on Ni-based electrocatalysts: the effect of metal doping. Catalysts 8, 454 (2018).

51. Sheng, W. et al. Correlating hydrogen oxidation and evolution activity on platinum at different $\mathrm{pH}$ with measured hydrogen binding energy. Nat. Commun. 6, 5848 (2015).

52. Zheng, J., Sheng, W., Zhuang, Z., Xu, B. \& Yan, Y. Universal dependence of hydrogen oxidation and evolution reaction activity of platinum-group metals on $\mathrm{pH}$ and hydrogen binding energy. Sci. Adv. 2, e1501602 (2016).

53. McCrum, I. T. \& Koper, M. T. M. The role of adsorbed hydroxide in hydrogen evolution reaction kinetics on modified platinum. Nat. Energy 5, 891-899 (2020).

54. Ravel, B. \& Newville, M. ATHENA, ARTEMIS, HEPHAESTUS: data analysis for X-ray absorption spectroscopy using IFEFFIT. J. Synchrotron Radiat. 12, 537-541 (2005).

55. Kresse, G. \& Hafner, J. Ab initio molecular dynamics for liquid metals. Phys. Rev. B 47, 558-561 (1993).

56. Kresse, G. \& Furthmüller, J. Efficient iterative schemes for ab initio totalenergy calculations using a plane-wave basis set. Phys. Rev. B 54, 11169-11186 (1996).

57. Kresse, G. \& Joubert, D. From ultrasoft pseudopotentials to the projector augmented-wave method. Phys. Rev. B 59, 1758-1775 (1999).

58. Blöchl, P. E. Projector augmented-wave method. Phys. Rev. B 50, 17953-17979 (1994).

59. Perdew, J. P., Burke, K. \& Ernzerhof, M. Generalized gradient approximation made simple. Phys. Rev. Lett. 77, 3865-3868 (1996).

60. Cockayne, E. \& Nelson, E. B. Density functional theory meta-GGA + U study of water incorporation in the metal-organic framework material Cu-BTC. J. Chem. Phys. 143, 024701 (2015).

61. Zhao, S. et al. Ultrathin metal-organic framework nanosheets for electrocatalytic oxygen evolution. Nat. Energy 1, 16184 (2016).
62. Zhang, B. et al. High-valence metals improve oxygen evolution reaction performance by modulating $3 \mathrm{~d}$ metal oxidation cycle energetics. Nat. Catal. 3, 985-992 (2020).

63. Liu, M. et al. Enhanced electrocatalytic $\mathrm{CO}_{2}$ reduction via field-induced reagent concentration. Nature 537, 382-386 (2016).

\section{Acknowledgements}

This work is supported by the National Basic Research Program of China (Grant 2018YFA0702001), the National Natural Science Foundation of China (Grants 21975237 and 51702312), the Anhui Provincial Research and Development Program (Grant 202004a05020073), the Fundamental Research Funds for the Central Universities (Grant WK2340000101), the USTC Research Funds of the Double First-Class Initiative (Grant YD2340002007), and the Recruitment Program of Global Youth Experts. Y.D.

acknowledges the China Postdoctoral Science Foundation (2020M682008, 2020TQ0309).

\section{Author contributions}

M.R.G. conceived and supervised the project. S.Q. and Y.D. performed the experiments, collected and analyzed the data. X.L.Z carried out the DFT calculations. X.S.Z. and J.F.Z. performed XPS measurements. L.-R.Z. collected and analyzed the XANES data. F.Y.G., P. P.Y., Z.Z.N., R.L., and Y.Y. helped with electrochemical data collection and analysis. M.R. G. and S.Q. co-wrote the manuscript. All authors discussed the results and commented on the manuscript.

\section{Competing interests}

The authors declare no competing interests.

\section{Additional information}

Supplementary information The online version contains supplementary material available at https://doi.org/10.1038/s41467-021-22996-2.

Correspondence and requests for materials should be addressed to M.-R.G.

Peer review information Nature Communications thanks Dario Dekel, Yun Wang, and other, anonymous, reviewers for their contributions to the peer review of this work. Peer review reports are available.

Reprints and permission information is available at http://www.nature.com/reprints

Publisher's note Springer Nature remains neutral with regard to jurisdictional claims in published maps and institutional affiliations.

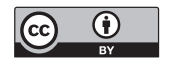

Open Access This article is licensed under a Creative Commons Attribution 4.0 International License, which permits use, sharing, adaptation, distribution and reproduction in any medium or format, as long as you give appropriate credit to the original author(s) and the source, provide a link to the Creative Commons license, and indicate if changes were made. The images or other third party material in this article are included in the article's Creative Commons license, unless indicated otherwise in a credit line to the material. If material is not included in the article's Creative Commons license and your intended use is not permitted by statutory regulation or exceeds the permitted use, you will need to obtain permission directly from the copyright holder. To view a copy of this license, visit http://creativecommons.org/ licenses/by/4.0/.

(C) The Author(s) 2021 